\title{
STUDIES ON SYNTHETIC EVALUATION
}

OF SCIBFWIIFIC RESEARCH OUTCOMES

By Theng Hin, Ii Changshun, Thou Qingwen, Chen Guangyi, If Yamin, Cheng Gang, qu Xuxin,

(Hebei Agricult tural University, China)

\section{ABSTRACT}

In this paper, the application of Analytic Hierarchy Process ( A H P ) to synthetic evaluation of scientific research outcomes were studied. The outcomes were divided Into faur types; A---- new technology and new products; D---soft sciences; G--- basic theory and Q--_ extension and popularization. The four hierarchy models for each type and twenty-one judge matrices vere constructed on the basis of expert consultation. By solving the matrices to find the eigenvectors, the importance weights of evaluation indexes were obtained, and the evaluation forms were also designed. Thus, a new method for deciding the awards of science and technology development was suggested. Its application showed that the method gave satisfactory results.

At present time, science and technology develop rapidly, and outcomes of sclentific researches increase with each passing day. It is a important task for science and technology managerial personnel to improve the level of manegement. This study on 't The synthetic evaluation of scientifle research outcomes" includes (Ii) Which factors and how these factors make up the outcomes of scientiflc researches? (2) thich indexes are taken into account by scientific research management departments of different levels when deciding on the awards of science and technology development? And what is the relationship between the Indexes and tho make-up factors of research outcomes? (3) Develop a new method for deciding on axards of science and technology development, which is more reasonahle and more practicisl.

I. The analytic hierarchy process ( $A$ H $P$ ) is main methodolceical approach th mathematical basis in this study. - IHP was established by professor T.I. Sacty. an imerican operations researcher, in 1973 and was introduced to China by his student H. Gholawiezhad in 1982. Hany appilcetions of the AHP have proved that It is reasonalie and practical for various purposes. Everything has its internal hierarchy, so does in people's thinking process. AHP is a project of making decision according to object's herarchy and people's thinking process. Firstly the hierarchy model should be constructed and then ke evaluated by experts. Then the welght numbers of correlative factors of the object can be achieved by quantifying evaluation results, constructing judgement matrices and solving the elgenvectors of each judgement matrix. Finaliy, the quantitatively synthetic evaluation, which provides scientific basis for decision, can be achieved according to the weight mmbers.

The principle procedure of AHP is to construct a set of matrices equations according to the pairuise synthetic evaluation of several experts to the factors of a certain object and the decision can be made through cal culating normalized weight numbers of each factor.

\section{The procedures of AHP are as folions:}

1. Investifate and study carefully the overall structure and each decision factor of an object to be evaluated, then construct a reasonable mathematical model of AhP. 
2. Invite a group of experts who are typical representatives to evaluate the model, 1.e. to do pairwise comparison of qualitative importance to sach factor of each hlerarchy and maxis" "In the grade column. There are 1-9 scale which are classifled into 5 grades. All these steps are the preparation for $q$ quántitative analysis.

\section{Construct a set of matrices.}

4. iDo Iocal priorities and consistency check to each matrix.

5. Do global prlority and consistency check. The elgenvector W of global priorfty is the normaliz ed priority welght numbers of correlative factors of syntheitic evaluation.

6. Invite another group of experts to evaluate concrete cbjects again in the same way. Multiplying the corresponding numbers of evaluations from each evaluation, the resulted sim of that multiplication is the final result of the evaluations.

II. Constructins mathematical model of AHP

According to their nature, the outcomes of scientific researches were divided into $A, D, G$, and $\bar{Q}$ type, the criterion hierarchy of the synthetic evaluation model was made up of several aspects of research outcomes or several aspects Involved in the evaluation of research, and the index hierarchy was made up of several correlative factors which made up the research outcomes or the factors * related to the synthetic evaluation. Thus four mathematical models of AHP were - coństructed.

1. Type $\dot{A}:$ research outcomes of new technology and new product

This type of outcomes can be directly put into production or applied to a certain production department to ing about the obvious economic benefit that

- can/be caliculated financialiy.

$\rightarrow+1$

$7: 2$ : Type Ds: soft scilence research outcomes

$\because *$

2 This type of researches; such as reglonal planning, resource survey and allocation, management of sclentific researches, compute programming, test or measurement method, planning polfcy and training of personnel, etc. are carried "out for the reasons of polfcy decision or the goals of whole soclety. These researches have obvious soctal benefit, but the econonic benefit is hard to calculate financially.

3. Type G: besic theory researches

This type of research outcomes is the one with knowledges and is signigicant to a certain subject. Still it has obvious social benefit.

4. Type Q: research on popularization and extension

This type of researches works with the extension and popularization of the research outcomes such as introducing advanced technology, improving the technfques in the light of special conditions, etc. This kind of outcomes should bring.about signifjcant economic benefits, or accelerate the development of national economics into certain extent 
Fit.

8
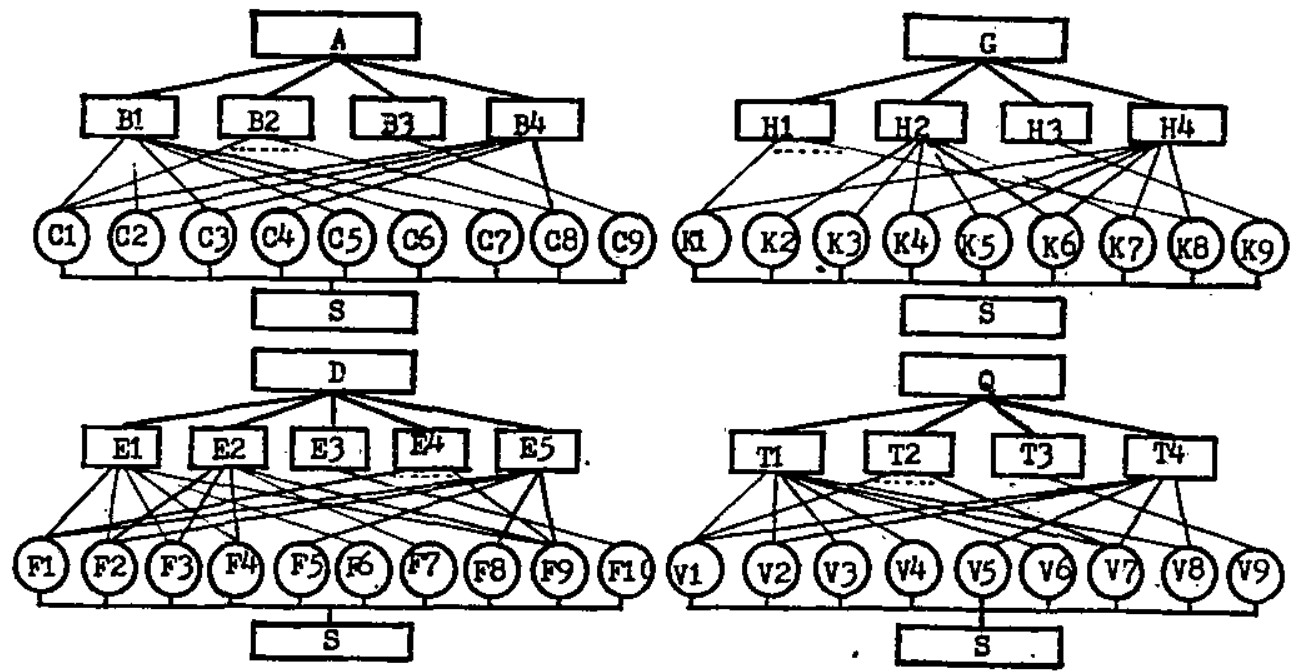

8

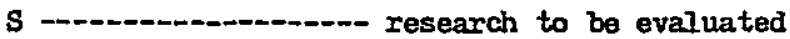

A, D, G, Q -......... synthetic evaluation of research

$\mathrm{B1}$, 퍼, H2, TI -..--- benefit

$\mathrm{B2}, \mathrm{B} 4, \mathrm{H1}, \mathrm{T2}$-.-.- level

C9, $110, \mathrm{K9}$, v9

$\mathrm{B3}, \mathrm{E3}, \mathrm{H3}, \mathrm{T3}$,

C1. F9, V7, K7 -..-.-- seIf-confldence of evaluation staff

C3. $\mathrm{F2}, \mathrm{K} 4, \mathrm{~V} 2$-...... soctal benefit

$\mathrm{CB}, \mathrm{K8}, \mathrm{v8}, \mathrm{F} 8$-...-- Bcope and efficiency

C2, $\mathrm{M}, \mathrm{V1}$

$\mathrm{BH}, \mathrm{B5}, \mathrm{T} 4 \mathrm{-n}$

$\mathrm{H} 4, \mathrm{~F} 5, \mathrm{~V} 5$-......-.- complexi ty

0

C4, $\mathrm{KI}$

C5, K2 -......-- academic Innovation

C6 1 -...-..- technical level

E2 - -

F3 -............... effect and influence

F4 - -

F6 - - Innovation and Ievel

F7 - maturation and perfection

K5 -------ocial effect

K6

$\mathrm{K} 3$

V3

v6

--_---- academic significance

-...-...-..- academic level

-

- level reached after the research being extended (new level)

14

innovative skill 
III. Evaluating the four mathematical models of AHP

Based on the four models, the evaluating forms corresponding with each nodel were designed. In order to get more accurate data, thirty experts were invited to Blve valuations. Amorig the experts, fifteen of them ware the heads of scientifflc research department, science and technology commission of hebel province, districts or cities. The others were scientists or technologists from provincial acadeny of agricul tural sclences, academy of sclences, and universities. For the purpose of processing the evaluation data, the comparative signs $(>$, $=$, $\langle$ ) of the importance between correlative factors were used. According to the opintons of the most experts, the amthmetical means were calculated to make the valuations quantifying. Ail these procedures resulted in four synthetilc tabiles of the data. ( to be abbreviated )

IV. Constructing Judgement matrix and doing locai prilorities in order to determine the priortity of the factors In index hierarchy relatively to goal hierarchy. This is expressed on the right. Generaly the local prior ty

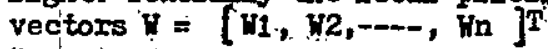
were achieved $w$ th radical root method:

\begin{tabular}{|c|c|c|c|}
\hline $\mathbf{A}$ & $\mathrm{BI}$ & B2- - . & $\mathbf{u}$ \\
\hline $\begin{array}{l}\mathrm{B} 1 \\
\mathrm{~B} 2\end{array}$ & $\begin{array}{l}b 11 \\
b 21\end{array}$ & bi2 & $\begin{array}{l}\text { W1 } \\
W 2\end{array}$ \\
\hline $\mathrm{Bn}$ & bnt & bn2 & Un \\
\hline
\end{tabular}

a. Calculate the multiplication of all el ements of each row:

$$
\text { Mil }=\prod_{j=1}^{n} \text { bij }
$$

b. Calculate the nth root of $\mathrm{Mil} \quad \overline{\mathrm{W}}=\sqrt[n]{\mathrm{WI}}$

c. FInd eigenvectors: $\quad H=T / \sum_{j=1}^{n} W$,

d. Find the maximum efgevalue of the matrix $\lambda_{\max }=\sum_{j=1}^{i n} \frac{(\text { AW }) i}{\text { nWI }}$, where (AW) I respects the 1 th element of vector All:

e. Calculate consistency indexi CI $=\frac{\lambda_{\max -n}}{n-1}$.

f. The average randon consistency indexs RI are:

$\begin{array}{lllllllll}1 & 2 & 3 & 4 & 5 & 6 & 7 & 8 & 9\end{array}$

$\begin{array}{lllllllll}0 & 0 & 0.58 & 0.90 & 1.12 & 1.24 & 1.32 & 1.41 & 1.45\end{array}$

g. Find random consistency ratios $\quad \mathrm{GR}=\frac{\mathrm{CI}}{\mathrm{RI}}<0.10$

1. Actording to the above formulas, the mathematical model of synthetic evaluation on sclentiflc research outcomes of type $A$ is achieved as follows:

(1). Construct judgement matrix $A-B$ and compare the relative inportance among the criteria to the overall goal of synthetic evaluation. Below are the relative importance weights: 


\begin{tabular}{|c|c|c|c|c|c|}
\hline$A$ & $B 1$ & $B 2$ & $B 3$ & $B 4$ & $y$ \\
\hline$B 1$ & 1 & 2.86 & 4.68 & 4.15 & 0.53 \\
$B 2$ & $1 / 2.86$ & 1 & 2.88 & 3.68 & 0.27 \\
$B 3$ & $1 / 4.68$ & $1 / 2.88$ & 1 & $1 / 1.95$ & 0.09 \\
$B 4$ & $1 / 4.15$ & $1 / 3.68$ & 1.95 & 1 & 0.12 \\
\hline
\end{tabular}

$\lambda_{\max }=4.15, \quad \mathrm{CI}=0.05, \quad \mathrm{RI}=0.90, \quad \mathrm{CR}=0.05$

(2). Construct judgement matrix BI-C and compare the relative importance emong correlative indexes to benefit criterion. Belou are the relative importance weights?

\begin{tabular}{|c|c|c|c|c|c|c|c|}
\hline $\mathrm{B} 1$ & $\mathrm{C1}$ & $\mathrm{C2}$ & $\mathrm{C3}$ & $\mathrm{C5}$ & $\mathrm{C6}$ & $\mathrm{CF}$ & W \\
\hline $\mathrm{C1}$ & 1 & $1 / 4.05$ & $1 / 3.23$ & $1 / 3.22$ & $1 / 2.53$ & $1 / 2.78$ & 0.05 \\
$\mathrm{C2}$ & 4.05 & 1 & 3.38 & 3.34 & 2.78 & 2.77 & 0.36 \\
$\mathrm{C3}$ & 3.23 & $1 / 3.38$ & 1 & $1 / 2.55$ & $1 / 2.48$ & $1 / 2.91$ & 0.09 \\
$\mathrm{C5}$ & 3.22 & $1 / 3.35$ & 2.55 & 1 & 2.88 & 1.48 & 0.21 \\
$\mathrm{C6}$ & 2.54 & $1 / 2.78$ & 2.48 & $1 / 2.88$ & 1 & $1 / 2.39$ & 0.12 \\
$\mathrm{C7}$ & 2.78 & $1 / 2.27$ & 2.91 & $1 / 1.49$ & 2.39 & 1 & 0.19 \\
\hline
\end{tabular}

(3). Construct judgement matrix B2-C and compare the relative importance among correlative indexes to level criterior. Below are the relative importance weights:

\begin{tabular}{|c|c|c|c|c|r|r|r|r|c|}
\hline $\mathrm{B} 2$ & $\mathrm{C1}$ & $\mathrm{C} 2$ & $\mathrm{C3}$ & $\mathrm{C4}$ & $\mathrm{C5}$ & $\mathrm{C6}$ & $\mathrm{C7}$ & $\mathrm{CB}$ & $\mathrm{W}$ \\
\hline $\mathrm{C} 1$ & 1 & $1 / 4.05$ & $1 / 3.23$ & $1 / 2.66$ & $1 / 3.29$ & $1 / 2.53$ & $1 / 2.78$ & $1 / 2.19$ & 0.04 \\
$\mathrm{C2}$ & 4.05 & 1 & 3.38 & 3.66 & 3.35 & 2.78 & 2.27 & 4.01 & 0.29 \\
$\mathrm{C3}$ & 3.23 & $1 / 3.38$ & 1 & 2.20 & $1 / 2.55$ & $1 / 2.48$ & $1 / 2.91$ & 2.35 & 0.09 \\
$\mathrm{C4}$ & 2.66 & $1 / 3.66$ & $1 / 2.20$ & 1 & $1 / 2.81$ & $1 / 2.37$ & $1 / 3.03$ & 1.85 & 0.07 \\
$\mathrm{C5}$ & 3.22 & $1 / 3.35$ & 2.55 & 2.81 & 1 & 2.88 & $1 / 1.48$ & 3.05 & 0.16 \\
$\mathrm{C6}$ & 2.54 & $1 / 2.78$ & 2.48 & 2.37 & $1 / 2.89$ & 1 & $1 / 2.39$ & 2.99 & 0.11 \\
$\mathrm{C7}$ & 2.78 & $1 / 2.27$ & 2.91 & 3.03 & 1.49 & 2.39 & 1 & 3.25 & 0.19 \\
$\mathrm{C8}$ & 2.19 & $1 / 4.01$ & $1 / 2.35$ & $1 / 1.85$ & $1 / 3.091 / 2.99$ & $1 / 3.25$ & 1 & 0.05 \\
\hline
\end{tabular}

(4). Construct judgement matrix B4-C and compare the relative importance mmong correlative indexes to scope criterion. Below are the relative inportance weights:

\begin{tabular}{|c|c|c|c|c|c|c|}
\hline B4 & C1 & C2 & 63 & C4s & $\mathrm{CB}$ & 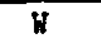 \\
\hline $\begin{array}{l}\text { c1 } \\
\text { C2 } \\
63 \\
04 \\
c 8\end{array}$ & $\begin{array}{l}1 \\
4.05 \\
3.23 \\
2.66 \\
2 / 19\end{array}$ & $\begin{array}{l}1 / 4.05 \\
1 \\
1 / 3.38 \\
1 / 3.66 \\
1 / 4.01\end{array}$ & $\begin{array}{c}1 / 3.23 \\
3.38 \\
1 \\
1 / 2.2 \\
1 / 2.35\end{array}$ & $\begin{array}{c}1 / 2.66 \\
3.66 \\
2.2 \\
1 \\
1 / 1.85\end{array}$ & $\begin{array}{r}1 / 2.19 \\
4.01 \\
2.34 \\
1.85 \\
1\end{array}$ & $\begin{array}{l}0.07 \\
0.46 \\
0.22 \\
0.15 \\
0.11\end{array}$ \\
\hline
\end{tabular}


(5). Do global priority of hierarchy $C$ and its colsistency check. Construct judgement matrix and calculate according to the following formulas:

Weights of global priority: $W=\sum_{i=1}^{n}$ bi ci

Consistency check: $\mathrm{CI}=\sum_{i=1}^{n}$ bI $\mathrm{CI} ; \mathrm{RI}=\sum_{i=1}^{n}$ bi $\mathrm{RI} ; \mathrm{CR}=\mathrm{CI} / \mathrm{RI}<0.1$

\begin{tabular}{|c|c|c|c|c|c|}
\hline${ }^{1}$ & $\frac{B 1}{0.53}$ & $\begin{array}{r}\overline{\mathrm{B} 2} \\
0.27\end{array}$ & B3 & $\frac{\mathrm{B} 4}{0.12}$ & global priority of \\
\hline $\begin{array}{l}101 \\
02 \\
03 \\
03 \\
04 \\
05 \\
106 \\
07 \\
108 \\
09\end{array}$ & $\begin{array}{l}0.05 \\
0.36 \\
0.08 \\
0.21 \\
0.12 \\
0.19\end{array}$ & $\begin{array}{l}0.04 \\
0.29 \\
0.09 \\
0.07 \\
0.16 \\
0.11 \\
0.19 \\
0.05\end{array}$ & 1.00 & $\begin{array}{l}0.07 \\
0.46 \\
0.22 \\
0.15 \\
\\
0.11\end{array}$ & $\begin{array}{l}0.05 \\
0.32 \\
0.09 \\
0.04 \\
0.15 \\
0.09 \\
0.15 \\
0.03 \\
0.09\end{array}$ \\
\hline
\end{tabular}

$$
\text { I } C I=0.07, \quad{ }_{\text {RI }}=1.17, \quad \mathrm{CR}=0.06
$$

2. The Index nelghts for the research outcomes of type D, G, Qalso can be achieved with the sante method as above. (The calculation process is attreviated. )

v. The results of the study

1. After dofng corisistency check for each matrix it was found that each CI was less than 0.1 . This showed that all twenty-one matrices had satisfled corsistency. The data used were reliable and the results were correct.

2. The importance weights of correlative factors of four type outcomes of scientific researches were obtalned ( confer the model):

\begin{tabular}{|c|c|c|c|c|c|c|c|c|c|}
\hline \multicolumn{2}{|c|}{$\begin{array}{l}\text { Type A } \\
\text { New Technolcey } \\
\text { \& New Product }\end{array}$} & \multicolumn{3}{|c|}{$\begin{array}{l}\text { Type D } \\
\text { So:t. Science } \\
\text { Researches }\end{array}$} & \multicolumn{2}{|c|}{$\begin{array}{l}\text { Type'G } \\
\text { Baste Theory } \\
\text { Researches }\end{array}$} & \multicolumn{3}{|c|}{$\begin{array}{l}\text { Type } Q \\
\text { Researches or, } \\
\text { Extension }\end{array}$} \\
\hline $\begin{array}{l}c 1 \\
c 2 \\
c 3 \\
.04 \\
05 \\
06 \\
0 \% \\
08 \\
09\end{array}$ & $\begin{array}{r}0.05 \\
0.32 \\
0.09 \\
0.04 \\
-0.15 \\
0.09 \\
0.15 \\
0.03 \\
0.09\end{array}$ & $\begin{array}{l}\text { F1 } \\
\text { F2 } \\
F 3 \\
F 4: \\
F 5 \\
F 6 \\
F 7 \\
F 8 \\
\text { F9 } \\
\text { F10 }\end{array}$ & $\begin{array}{l}0.05 \\
0.19 \\
0.14 \\
0.12 \\
0.02 \\
0.22 \\
0.11 \\
0.02 \\
0.06 \\
0.08\end{array}$ & $\vdots$ & $\begin{array}{l}\mathrm{KI} \\
\mathrm{K} 2 \\
\mathrm{~K} 3 \\
\mathrm{~K} 4 \\
\mathrm{~K} 5 \\
\mathrm{~K} 6 \\
\mathrm{~K} ? \\
\mathrm{~K} 8 \\
\mathrm{~K} 9\end{array}$ & $\begin{array}{r}0.05 \\
0.19 \\
0.13 \\
0.12 \\
0.09 \\
0.22 \\
0.07 \\
0.03 \\
0.12\end{array}$ & $\begin{array}{l}\text { v1 } \\
\text { v2 } \\
\text { v3 } \\
\text { v4 } \\
\text { v5 } \\
\text { v6 } \\
\text { v7 } \\
\text { v8 } \\
\text { v9 }\end{array}$ & $\begin{array}{l}0.34 \\
0.19 \\
0.06 \\
0.10 \\
0.04 \\
0.08 \\
0.05 \\
0.07 \\
0.08\end{array}$ & 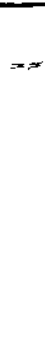 \\
\hline
\end{tabular}

3. Using the above mentioned weights, four-type synthetic evaluation forms for 
each type of scientific reseerches were designed ( to the abbreviated ). The different evaluation Indexes were posed due to different types of researches and were given different weights according to the calculation. There were 1-9 scales which were divided into 5 grades. Scale 9 integrated the quantitative standard of the top awards in provincial level. Scale 7 integrated the quantitative standard of the top awards in district or city level. The quantitative judgement of a research, that were made by about mine experts in the sane fleld by marking " "on the evaluation forms, were integrated by reexaminer. In order to avoid obviously subjectlve errors, the highest and the lowest evaluation numgers should be deleted and the mean of the evaluation numbers was calculated. This yielded the quantitative evaluation $R I$ of a certain evaluation index. Below is the weight synthesis of weight numgers of the correlative factors:

$$
N=\sum_{i=1}^{n} W i j \text { Rij, where Wij, Ris are the inftial weight num- }
$$

bers and quantitative evaluation of each index; and $N$ is the total score.

4. We have dentgned the computer programme for deciding on awards of scilence and technology development. The discs are avallable for those instituties in where a lot of research outcomes are being evaluated. Through data processing, the computer can list the classified priorities of four-type researches and the priority of all researches. It can also analyse quantitatively the evaluation quality of evaluation staff.

VI. Discussion

1. To evaluate the outcomes of scientific researches more reasonably and pricisely., various mathematical anaiysis mathods have been applied and have made the qualitative judgement quantifying, obtaining the synthetic and quantitative evaluation. However, how to choose inftial data correctly and how to 'avoid the infliuences froja the valuator's subject projudice are still remained to be studied and perfected.

- 2. The integration of experts' evaluation and the decision from the administrative levels is the core of the synthetic evaluation suggested in this paper. In the course of the evaluation, what need the valuators to do is only to nark: " $\checkmark$ " on the forms qulitatively accordirg to their orn judgemient. Then the reexaminex will make the evaluation quantifying and get the priorlty of every research outcomes. Based on this priority, the management department or evaluation commission can easily decides the outcomes awarded and their prize grades.

3. In this study, the research outcomes were divided into $A, D, G$, and $Q$ type and the hlerarchy model for each type was designed. Based on the thirty experts' evaluation, the index weights for each type were noted for their exactness. The evaluation forms were simple, clear, exict and suitable for deciding on the awards. Besides, two indexes, authoritativeness of evaluation commission and self-confidence of the valuators were also involved into the ovexall make- up factors of the synthetic evaluation, al though they were not the make-up factors of research outcomes. The evaluation forms we designed have following charactors:

(1). The evaluation is highly exact, because the forms are designed according to different types of research outcomes. 
(2). The indexes are clear, concrete and highly quantitative. Still thdy are easily contirolled by valuators.

(3). On the forms we set scale 9 as the quantitative index according to the top arard criteris of provincial levie and scale 7 according to the top award criteria of district or city level. We syrthesize all the gvaluation criteria of provincial district and city levels in one form. So the forms are more practical and suitable for wide ranges.

(4). The results of our evaluation mathod are prioxities and the total score which reflect the quality of the research outcomes. So this method can be applied in wide ranges.

(5). In the system of microcomputer evaluation, $w \in$ have designed the programe of evaluation exactness of expert-group and evaluation exactness of expert. Therefore, both qualities of the research outcomes and the evaluatior quality of experts are evaluated simultaneously. That is helpful to avoid subject factors from valuators and to improve evaluation effectiveness.

4.: Howadays the trend of evaluation on scientific research outcomes is quantifative Indexes, al though methods and indexes used are different. And the evaluation forms axe designed in setting several indexes, giving a set of weight numbers and synthesizing evaluation quantitatively. That is not only the trend but also the advanced level of science and technology management.

REFERERCES

1. HE. J . S . (1985). Inquify on the synthetic evaluation of scientific research by AHP. Theory and Practice of System Engineering $5(1), 33--38$. (In Chinese)

2. IIU . B . (1984). Analysis hierarchy process --.-the mean of planning and decision. System Engineering 2 (2): 22--30. (In Chinese)

3.|Saaty . T . I . (1980). The Analytic Hierarchy Process. MCGRAH-HIIL INTERNATIONAL BOOK COMPANY.

4. ZHAO . H . C . (1986). Analysis hiexarchy process. Science publishing house (In Chinese)

5. ZHEN . M. (1987). Study on the distribution of scientiflic research

finance by AHP. Journal of Hebei Agricultural University 10 (4): 106-113. (In Chinese) 